\title{
Electrochemical Kinetics of the Hydrogen Reaction on Platinum in Concentrated $\mathrm{HCl}(\mathbf{a q})$
}

\author{
Derek M. Hall ${ }^{\mathrm{a}, \mathrm{b}}$, Justin R. Beck ${ }^{\mathrm{a}}$, Serguei N. Lvov ${ }^{\mathrm{a}, \mathrm{b}, \mathrm{c}, *}$ \\ ${ }^{a}$ The EMS Energy Institute, \\ ${ }^{\mathrm{b}}$ Department of Energy and Mineral Engineering \\ ${ }^{\mathrm{c}}$ Department of Materials Science and Engineering \\ The Pennsylvania State University, University Park, PA 16802, USA \\ *Corresponding author: 207 Hosler Building University Park, PA 16802, USA. (814)-863-8377, \\ lvov@psu.edu
}

\begin{abstract}
The hydrogen reaction in concentrated $\mathrm{HCl}(\mathrm{aq})$ solutions is a key reaction for the $\mathrm{CuCl}(\mathrm{aq}) / \mathrm{HCl}(\mathrm{aq})$ electrolytic cell. Here, electrochemical impedance spectroscopy (EIS) and linear sweep voltammetry (LSV) were used to obtain new data for the hydrogen reaction on platinum submerged in highly concentrated acidic solutions at $25^{\circ} \mathrm{C}$ and $0.1 \mathrm{MPa}$. LSV and EIS data were collected for $\mathrm{Pt}$ in $0.5 \mathrm{~mol} / \mathrm{L} \mathrm{H}_{2} \mathrm{SO}_{4}(\mathrm{aq}), 1 \mathrm{~mol} / \mathrm{L} \mathrm{HCl}(\mathrm{aq})$ and $7.71 \mathrm{~mol} / \mathrm{L} \mathrm{HCl}(\mathrm{aq})$ solutions. It was found that exchange current density $\left(j_{0}\right)$ values varied between 1 and $2 \mathrm{~mA} / \mathrm{cm}^{2}$. An equivalent circuit model was used to obtain comparable $j_{0}$ and limiting current density values from EIS data relative to values obtained with LSV data. It was found that as the concentration of acid increased, a noticeable decrease in the performance was observed.
\end{abstract}

\section{Introduction}

One of the most important electrochemical reactions for the $\mathrm{CuCl}(\mathrm{aq}) / \mathrm{HCl}(\mathrm{aq})$ electrolytic cell is the hydrogen reaction, $2 \mathrm{H}^{+}(\mathrm{aq})+2 \mathrm{e}^{-} \leftrightarrow \mathrm{H}_{2}(\mathrm{aq})$ [1]. For this electrolytic cell, the use of highly concentrated $\mathrm{HCl}(\mathrm{aq})$ is needed to both avoid copper deposition at the cathode and to increase the solubility of $\mathrm{CuCl}(\mathrm{s})$ and $\mathrm{CuCl}_{2}$ (s) that permeates through the membrane [1]. However, no available data or predictions were found for the electrochemical kinetics of the HER reaction at low overpotentials in highly concentrated $\mathrm{HCl}(\mathrm{aq})$ solutions. In low concentration acids, the estimated exchange current densities ranges from 70 to $0.1 \mathrm{~mA} / \mathrm{cm}^{2}$, depending on the experimental system with no clear relations to variables such as $\mathrm{pH}$, anion concentration and $\mathrm{H}_{2}$ (aq) concentrations [2]. These current limitations make determining the overpotential contribution for the $\mathrm{HER}$ reaction in highly concentrated $\mathrm{HCl}(\mathrm{aq})$ to the $\mathrm{CuCl}(\mathrm{aq}) / \mathrm{HCl}(\mathrm{aq})$ electrolytic cell overpotential difficult. For the further development of this technology, it is important to identify and quantify the sources of overpotential for this electrochemical process to better focus future research.

Recent studies have focused on reducing the amount of platinum used in the $\mathrm{CuCl}(\mathrm{aq}) / \mathrm{HCl}(\mathrm{aq})$ electrolytic cell design [3]. For this particular electrochemical cell, evidence suggested that the HER reaction kinetics, not the anodic kinetics may be the largest contributor to the cell's overpotential [3]. To better understand the nature of the cathode's overpotential, accurate electrochemical kinetic values for the HER reaction in concentrated $\mathrm{HCl}(\mathrm{aq})$ are needed. In this study, electrochemical impedance spectroscopy (EIS) and linear sweep voltammetry (LSV) data were collected from $-60 \mathrm{mV}$ to $100 \mathrm{mV}$ of overpotential $(\eta)$ in a number of high acidic aqueous solutions to understand the cathodic current for this electrochemical cell.

In moderately acidic solutions, previous research on the hydrogen reaction found that different mass transport limitations and active species concentrations can significantly impact the expected reaction rates [2,4-12]. Another complication is the possible influence of anion species. 
One previous study identified that small halide anion concentrations ( $\mathrm{mM}$ concentrations of $\mathrm{Br}^{-}$ (aq) and $\mathrm{I}^{-}(\mathrm{aq})$ ) acted as inhibitors and slowed the reaction kinetics [4]. Therefore, mass transport effects and concentrations of active species should be defined.

The rotating disc electrode (RDE) provides an equally accessible surface that useful for predicting the Nernst diffusion layer and its effects on electrochemical reactions. The so called generalized Butler-Volmer[13] (B-V) equation with limiting current values is one approach for using kinetic and mass transport values to predict experimental RDE data:

$$
j=\frac{e^{\frac{\alpha_{a} \eta F}{R T}}-e^{-\frac{\alpha_{c} \eta F}{R T}}}{\frac{1}{j_{0}}+\frac{e^{\frac{\alpha_{a} \eta F}{R T}}}{j_{\text {lim }, a}}-\frac{e^{-\frac{\alpha_{c} \eta F}{R T}}}{j_{l i m, c}}}
$$

where $j_{\text {lim,c }}$ and $j_{\text {lim,a }}$ are the limiting current density of the cathodic and anodic reaction, respectively. These limiting current values account for the mass transfer limitations from each direction of the half reaction. $\alpha_{\mathrm{a}}$ and $\alpha_{\mathrm{c}}$ are the anodic and cathodic transfer coefficients, $R=$ $8.3145 \mathrm{~J} \mathrm{~mol}^{-1} \mathrm{~K}^{-1}$ is the molar gas constant, $F=96485 \mathrm{C} \mathrm{mol}^{-1}$ is Faraday's constant, $T$ is the thermodynamic temperature and $j_{0}$ is the exchange current density. The measured current, $I$ for every potential, $E$, can be converted to current density, $j$, using the geometric surface area as an approximation for the real surface area of a finely polished surface. For the EIS data collected, an equivalent circuit analog can be used to estimate the $j_{l i m, c}$ and $j_{0}$ values. Mathematical expressions and the physical meanings for each of the circuit elements as they relate to electrochemical reactions were derived previously [14]. The equivalent circuit used comprised of the ohmic resistance, $R_{\mathrm{s}}$, the adsorption resistance, $R_{a}$, a bounded Warburg impedance, $Z_{\mathrm{w}}$, the adsorption capacitance, $C_{\mathrm{a}}$, and the high frequency capacitance, $C_{\mathrm{HF}}$ [14]. An image of the circuit can be found in Figure 3. From the fitting of this circuit, the following equation can be used to estimate the kinetic parameters represented by the $j_{0}$ term in Eq. (1) using $R_{a}$ :

$j_{0}=\frac{R T}{R_{a} n F A}$

where $A=0.19635 \mathrm{~cm}^{2}$ is the geometric surface area of the RDE tip used in this study and $n=2$ is the electron number of the half reaction. Using the bounded Warburg parameter, $R_{w}, j_{\text {lim }, c}$ can be estimated as [15]:

$j_{l i m, c}=\frac{R T}{R_{w} n F A}$

\section{Experimental}

A Pine Research Instrumentation RDE assembly with Polytetrafluoroethylene fittings was used to study the hydrogen reaction in 3 cases of acidic solutions, with case 1, 2 and 3 being defined as $0.5 \mathrm{~mol} / \mathrm{L} \mathrm{H}_{2} \mathrm{SO}_{4}(\mathrm{aq}), 1 \mathrm{~mol} / \mathrm{L} \mathrm{HCl}(\mathrm{aq})$ and $7.72 \mathrm{~mol} / \mathrm{L} \mathrm{HCl}(\mathrm{aq})$. Case 1 was selected as it has been tested previously with $\mathrm{Pt}$ via an RDE [5]. Cases 2 and 3 were tested due to their significance to $\mathrm{CuCl}(\mathrm{aq}) / \mathrm{HCl}(\mathrm{aq})$ electrolytic cells, which operate with $\mathrm{HCl}(\mathrm{aq})$ concentrations ranging from 1-10 mol/L with $7.72 \mathrm{~mol} / \mathrm{L}(8 \mathrm{~mol} / \mathrm{kg})$ being common [1,3]. Each solution was saturated with $\mathrm{H}_{2}(\mathrm{aq})$, purity $>99.999 \%$, produced from an Air Products 9200 hydrogen generator. The $\mathrm{H}_{2} \mathrm{SO}_{4}(\mathrm{aq})$ solution was $0.5 \mathrm{~mol} / \mathrm{L}$ solution from Alfa Aesar and the $\mathrm{HCl}(\mathrm{aq})$ 
solution was $1 \mathrm{~mol} / \mathrm{L}$ solution from $\mathrm{BDH}$ Chemicals. The $7.72 \mathrm{~mol} / \mathrm{L} \mathrm{HCl}(\mathrm{aq})$ solution was prepared from a Sigma Aldrich ACS reagent with a 0. 37 mass fraction stock solution and Millipore deionized water with conductivity of around $5.510^{-6} \mathrm{~S} / \mathrm{m}$. A three-electrode cell with an RDE was used for all electrochemical measurements. The working electrode was a Pt RDE tip, the counter electrode was a coiled Pt wire and the reference electrode was a Cole Parmer $\mathrm{Ag} / \mathrm{AgCl}$ electrode filled with $4 \mathrm{~mol} / \mathrm{L} \mathrm{KCl}(\mathrm{aq})$. The working electrode received a mirror finish using a microcloth with a Buehler $0.05 \mu \mathrm{m}$ alumina polish solution. Tests were run at $25{ }^{\circ} \mathrm{C}$ under a $0.1 \mathrm{MPa}$ hydrogen blanket. Electrochemical tests were performed using a Gamry Instruments Reference 600 potentiostat. Prior to all electrochemical measurements, cyclic voltammetry $(\mathrm{CV})$ screenings at $50 \mathrm{mV} / \mathrm{s}$ in the cathodic direction were performed between 0.2$1.3 \mathrm{~V}$ vs. the open circuit potential $\left(E_{O C P}\right)$ until the voltammograms displayed repeatable cycles. LSV data collected at $5 \mathrm{mV} / \mathrm{s}$ were corrected for $E_{O C P}$ and the ohmic drop $I R_{S}$ to display the xaxis in terms of $\eta$. The $R_{s}$ values obtained from EIS were used to correct for the ohmic drop and $E_{O C P}$ values were the measured potential difference between the working electrode and reference electrode at open circuit. The following equation was used to obtain $\eta$ :

$\eta=E_{\text {cell }}-E_{O C P}-I R_{s}$

where $I$ is the measured current and $E_{\text {cell }}$ is the measured cell potential. EIS data were collected at $E_{O C P}$ using a $10 \mathrm{mv}$ root mean square (rms) perturbation over a frequency range of 0.2-300000 $\mathrm{Hz}$ with 5 points/decade and fit using ZView software from Scribner. Frequencies below $0.2 \mathrm{~Hz}$ were not tested as previous studies found no significant change in trends between 0.01 and 0.2 $\mathrm{Hz}[9]$.

\section{Results}

The LSV data obtained via RDE for Case 1, $0.5 \mathrm{M} \mathrm{H}_{2} \mathrm{SO}_{4}(\mathrm{aq})$ was in agreement with similar data found in literature for both the HER[6] and HOR[2] polarizations in a low $\mathrm{pH}$ solutions. Varying the RDE rotation rate between 500 and 1600 rotations per minute (RPM) changed the $j_{\text {lim, }, a}$ from $2.4 \mathrm{~mA} / \mathrm{cm}^{2}$ to $1.4 \mathrm{~mA} / \mathrm{cm}^{2}$, but did not significantly alter the HER $E$ - $j$ dependence or $j_{\text {lim, }, ~}$ from $-0.14 \mathrm{~mA} / \mathrm{cm}^{2}$. Data in Figure 1 demonstrate the $E$ - $j$ trends observed for $0.5 \mathrm{M}$ $\mathrm{H}_{2} \mathrm{SO}_{4}(\mathrm{aq})(|\eta|<100 \mathrm{mV})$ and some conclusions about fitting the data with Eq. 1. From the figure, it can be seen that the fitting parameter extrapolated from the $\mathrm{H}_{2}$ pump method that matches those found with SECM in the presence of no halide anions, $j_{o}=70 \mathrm{~mA} / \mathrm{cm}^{2}$ with $\alpha_{\mathrm{a}}=\alpha_{\mathrm{c}}$

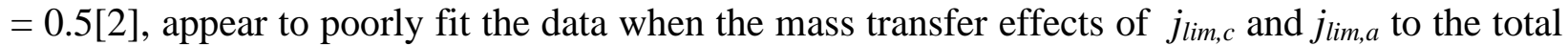
overpotential are taken into account(line, - - -). However, when we assume the Tafel-Volmer step for the transfer coefficients, $\alpha_{\mathrm{a}}=\alpha_{\mathrm{c}}=2$ [16,17], a $j_{o}$ of $2 \mathrm{~mA} / \mathrm{cm}^{2}$ fits the data with a chisquared goodness of fit of 0.002 and an $\mathrm{R}^{2}$ of 0.9996 . The $j_{o}$ obtained here is quite similar to the $j_{o}=1 \mathrm{~mA} / \mathrm{cm}^{2}$ found recently for the HER reaction in $0.5 \mathrm{M} \mathrm{H}_{2} \mathrm{SO}_{4}(\mathrm{aq})$ on multiple single crystal electrodes [5] and long ago on polycrystalline Pt [6].

Multiple sweeps were fit for Cases 1, 2 and 3 to obtain average fitting values for $j_{o}, j_{l i m, c}$ and $j_{\text {lim,a }}$ with standard deviations. Figure 2 compares the experimental data collected for each of the three Cases.

The differences between Case 1 and 2 are negligible in the HOR direction but some differences can be seen in the cathodic direction for all three cases. Overall, significantly increasing the 
presence of ions appeared to negatively impact $j_{o}$ and in Case 3 even $j_{l i m, c}$. For fitting Cases 1-3 with Eq. 1: $j_{0}$ values of $2.0 \pm 0.6,1.6 \pm 0.4$ and $1.2 \pm 0.1 \mathrm{~mA} / \mathrm{cm}^{2}$ were obtained; $j_{\text {lim, } a}$ values of $2.4 \pm 0.1,2.4 \pm 0.1$ and $1.5 \mathrm{~mA} / \mathrm{cm}^{2}$ were obtained and $j_{\text {lim, }}$ values of $-0.14 \pm 0.03,-0.11 \pm 0.02$ and $0.82 \pm 0.05 \mathrm{~A} / \mathrm{cm}^{2}$ were obtained, respectively.

An equivalent circuit with three parallel paths was used to check for agreement with the conclusions from LSV data using EIS data collected. One path used a Warburg impedance to model the impedance of a reaction limited by the diffusion of $\mathrm{H}_{2}$ (aq) with a negligibly small charge transfer reaction impedance, possibly the Volmer-Heyrovsky(rds) mechanism limited by diffusion of $\mathrm{H}_{2}(\mathrm{aq})$ between the bulk solution and electrode surface. The second path represented a reaction limited by an adsorption step such as the Tafel(rds)-Volmer mechanism. The final path was the charging of the electric double layer. An inductive element was added to fit the inductive behavior at high frequencies to improve the ease of obtaining $R_{s}$ (the high frequency point when the imaginary impedance is zero), typically attributed to the cell leads [15]. The EIS data in Figure 3 show the effects of increasing the concentration of ionic species on the electrochemical impedance. As the concentration of ionic species increased, the prominence of a mid-frequency $(100 \mathrm{~Hz})$ time constant increased, which can be correlated to a slower reaction.

Extracted $R_{a}$ values from EIS data resulted in $j_{o}$ values of $2.3 \pm 0.4,2.3 \pm 0.2$, and $1.4 \pm 0.01$ $\mathrm{mA} / \mathrm{cm}^{2}$ for Cases $1-3$. The average $j_{\text {lim, }}$ values calculated with $R_{w}$ values obtained from the EIS data were $2.3 \pm 0.2,2.0 \pm 0.1$ and $1.3 \pm 0.1 \mathrm{~mA} / \mathrm{cm}^{2}$, whereas LSV data obtained were 2.4 \pm 0.1 , $2.4 \pm 0.1$, and $1.5 \pm 0.1 \mathrm{~mA} / \mathrm{cm}^{2}$ for cases $1-3$. Therefore, reasonable enough agreement was found between EIS and LSV values [2]. Furthermore, increasing the concentration of ionic species between Cases 2 and 3 decreased the $j_{o}$ and $j_{\text {lim,c }}$ values, suggesting higher performance voltage efficiencies could be obtained if lower concentrations were used. Furthermore, no significant increases in $j_{o}$ values were obtained by increasing the acid concentration significantly. However, caution should be used when changing the $\mathrm{HCl}(\mathrm{aq})$ concentrations as it will eventually promote copper deposition [1]. Another possibility may be to further characterize the ion concentrationHER kinetics relationship for a series of catalyst materials in highly concentrated acid to see if $\mathrm{Pt}$ is in fact the best choice with respect to cost and performance.

It is important to note that these results are not implying that what was found here is the "true" $j_{0}$ [2] for an unimpeded elementary charge transfer step of HER/HOR reaction for all acidic media at the same temperature and pressure. However these results do provide (1) new data for the HER/HOR on a Pt surface submerged in highly concentrated acids with well-defined bulk concentrations of $\mathrm{H}^{+}(\mathrm{aq}), \mathrm{H}_{2}(\mathrm{aq})$ and well-defined hydrodynamics and (2) evidence that Eq. (1) can very accurately estimate the $\eta-j$ relationship for the HER/HOR reaction at Pt submerged in highly concentrated acidic solutions with small changes in $j_{o}, j_{\text {lim,a }}$ and $j_{\text {lim, }, ~}$, if $\alpha_{\mathrm{a}}=\alpha_{\mathrm{c}}=2$ is used.

\section{Conclusions}

New $E$ - $j$ data of the HER/HOR on Pt submerged in highly concentrated solutions were obtained. It was found that the data could be fit with the generalized Butler-Volmer equation, Eq. (1), and good agreement was obtained with previous data for Case $1\left[0.5 \mathrm{M} \mathrm{H}_{2} \mathrm{SO}_{4}(\mathrm{aq})\right]$. The new data showed that a decreased $\mathrm{pH}$ inadvertently increased the measured impedance and lowered performance. Assuming the Tafel step transfer coefficients of $\alpha_{\mathrm{a}}=\alpha_{\mathrm{c}}=2$, the LSV data could be easily fit with $j_{0}$ values between 1 and $2 \mathrm{~mA} / \mathrm{cm}^{2}, j_{\text {lim,c }}$ values between -0.8 and $-0.1 \mathrm{~A} / \mathrm{cm}^{2}$ and $j_{\text {lim, } a}$ values between 2.4 and $1.5 \mathrm{~mA} / \mathrm{cm}^{2}$. New EIS data and modeled with a circuit analog 
confirmed similar $j_{0}$ and $j_{\text {lim, }}$ values as obtained from LSV. Electrolytic systems relying on highly acidic solutions, such as the $\mathrm{CuCl}(\mathrm{aq}) / \mathrm{HCl}(\mathrm{aq})$ electrolytic cell, should consider the effects of highly acidic solutions on the electrochemical kinetics. If the concentrations of $\mathrm{HCl}(\mathrm{aq})$ is reduced, it may be possible to attain larger voltage efficiencies. Still, such changes should be made without compromising the role of $\mathrm{HCl}(\mathrm{aq})$ concentration to avoid copper deposition at the cathode.

\section{References}

[1] D.M. Hall, N.N. Akinfiev, E.G. LaRow, R.S. Schatz, S.N. Lvov, Thermodynamics and Efficiency of a CuCl(aq)/HCl(aq) Electrolyzer, Electrochim. Acta. 143 (2014) 70-82.

[2] J. Durst, C. Simon, F. Hasche, H.A. Gasteiger, Hydrogen Oxidation and Evolution Reaction Kinetics on Carbon Supported Pt, Ir, Rh, and Pd Electrocatalysts in Acidic Media, J. Electrochem. Soc. 162 (2015) 190-203.

[3] D.M. Hall, E.G. LaRow, R.S. Schatz, J.R. Beck, S.N. Lvov, Electrochemical Kinetics of $\mathrm{CuCl}(\mathrm{aq}) / \mathrm{HCl}(\mathrm{aq})$ Electrolyzer for Hydrogen Production via a $\mathrm{Cu}-\mathrm{Cl}$ Thermochemical Cycle, J. Electrochem. Soc. 162 (2015) F108-F114.

[4] J. Zhou, Y. Zu, A.J. Bard, Scanning electrochemical microscopy - Part 39. The proton/hydrogen mediator system and its application to the study of the electrocatalysis of hydrogen oxidation, J. Electroanal. Chem. 491 (2000) 22-29.

[5] H. Kita, S. Ye, Y. Gao, Mass-Transfer Effect in Hydrogen Evolution Reaction on Pt Single-Crystal Electrodes in Acid Solution, J. Electroanal. Chem. 334 (1992) 351-357.

[6] J.O. Bockris, I.A. Ammar, A.K.M.S. Huq, The Mechanism of The Hydrogen Evolution Reaction on Platinum, Silver and Tungsten Surfaces in Acid Solutions, J. Phys. Chem. 61 (1957) 879-886.

[7] S. Chen, A. Kucernak, Electrocatalysis Under Conditions of High Mass Transport: Investigation of Hydrogen Oxidation on Single Submicron Pt Particles Supported on Carbon, J. Phys. Chem. B. 108 (2004) 13984-13994.

[8] G.R. Engelhardt, R. Biswas, Z. Ahmed, S.N. Lvov, D.D. Macdonald, The use of channel flow cells for electrochemical kinetic studies in high temperature aqueous solutions, Electrochim. Acta. 52 (2007) 4124-4131.

[9] S. Sharifi-Asl, D.D. Macdonald, Investigation of the Kinetics and Mechanism of the Hydrogen Evolution Reaction on Copper, J. Electrochem. Soc. 160 (2013) H382-H391.

[10] S. Daniele, I. Lavagnini, M.A. Baldo, F. Magno, Steady state voltammetry at microelectrodes for the hydrogen evolution from strong and weak acids under pseudo-first and second order kinetic conditions, J. Electroanal. Chem. 404 (1996) 105-111. 
[11] A.C. Sun, W.D. Seider, Homotopy-continuation method for stability analysis in the global minimization of the Gibbs free energy, Fluid Phase Equilib. 103 (1995) 213-249.

[12] Y. Sun, J. Lu, L. Zhuang, Rational determination of exchange current density for hydrogen electrode reactions at carbon-supported Pt catalysts, Electrochim. Acta. 55 (2010) 844-850.

[13] A.J. Bard, L.R. Faulkner, Electrochemical Methods: Fundamentals and Applications, Second Edi, John Wiley \& Sons, New Jersey, 2001.

[14] M. Sluyters-Rehbach, Impedances of electrochemical systems: Terminology, nomenclature and representation - Part I: Cells with metal electrodes and liquid solutions (IUPAC Recommendations 1994), Pure Appl. Chem. 66 (1994) 1831-1891.

[15] Y. Matsuzaki, Electrochemical properties of a SOFC cathode in contact with a chromiumcontaining alloy separator, Solid State Ionics. 132 (2000) 271-278.

[16] E. Gileadi, Electrode Kinetics for Chemists, Chemical Engineers and Material Scientists, VCH publishers, New York, 1993.

[17] D. Landolt, Corrosion and Surface Chemistry of Metals, CRC press Inc, Boca Raton, FL, 2007.

\section{Figure captions}

Figure 1: Fitting results of $0.5 \mathrm{M} \mathrm{H}_{2} \mathrm{SO}_{4}$ data ( ) at 1600 RPM. [(Dashed line) Eq. 1: $j_{0}=70$ $\mathrm{mA} / \mathrm{cm}^{2}, \alpha_{\mathrm{a}}=\alpha_{\mathrm{c}}=0.5$; (Solid line) Eq. 1: $j_{0}=2 \mathrm{~mA} / \mathrm{cm}^{2}, \alpha_{\mathrm{a}}=\alpha_{\mathrm{c}}=2$; (Dotted Line) Eq. 1: $j_{0}=70$ $\left.\mathrm{mA} / \mathrm{cm}^{2}, \alpha_{\mathrm{a}}=\alpha_{\mathrm{c}}=2\right]$

Figure 2: $\eta-\log _{10} j$ experimental data of Case 1 (Dotted line), Case 2 (Grey dashed line) and Case 3 (Solid line) at 1600 RPM.

Figure 3: EIS data and model results on [A] Nyquist and [B] Bode plots. $\mathrm{a}(\bullet)=$ case 1 data with fit, $\mathrm{b}(\mathrm{\circ})=$ case 2 data with fit, $\mathrm{c}(\bullet)=$ case 3 data with fit. 


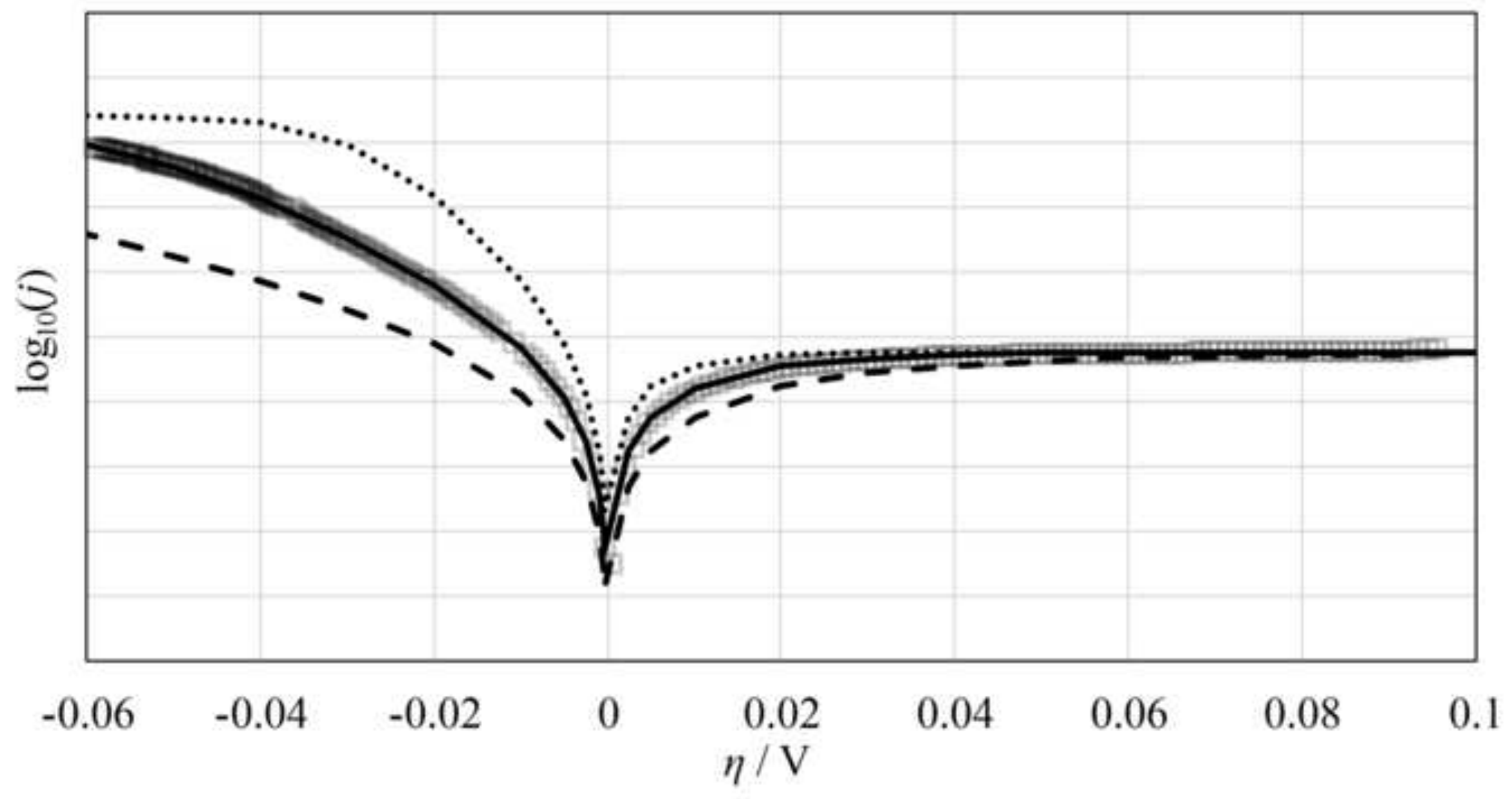




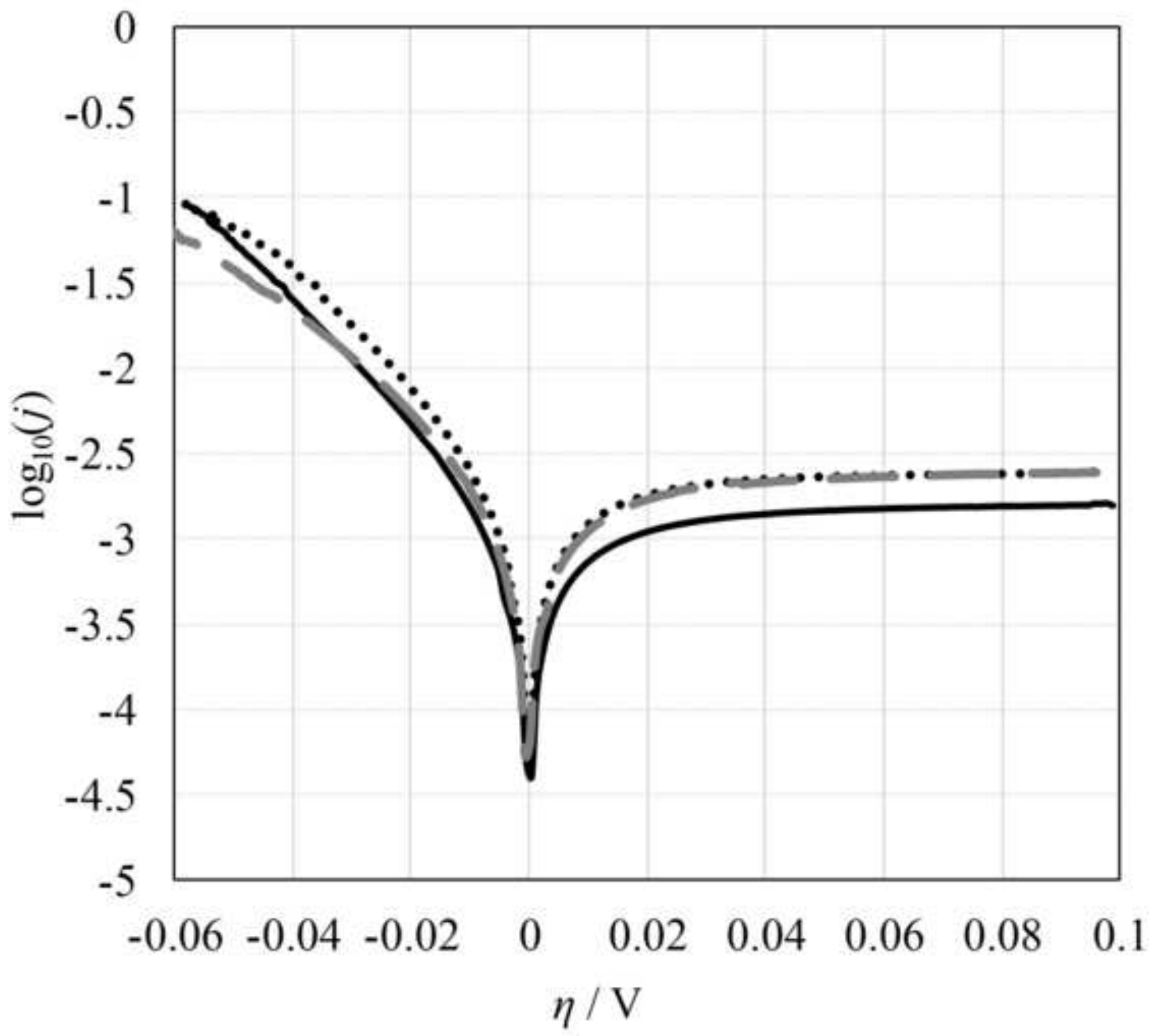



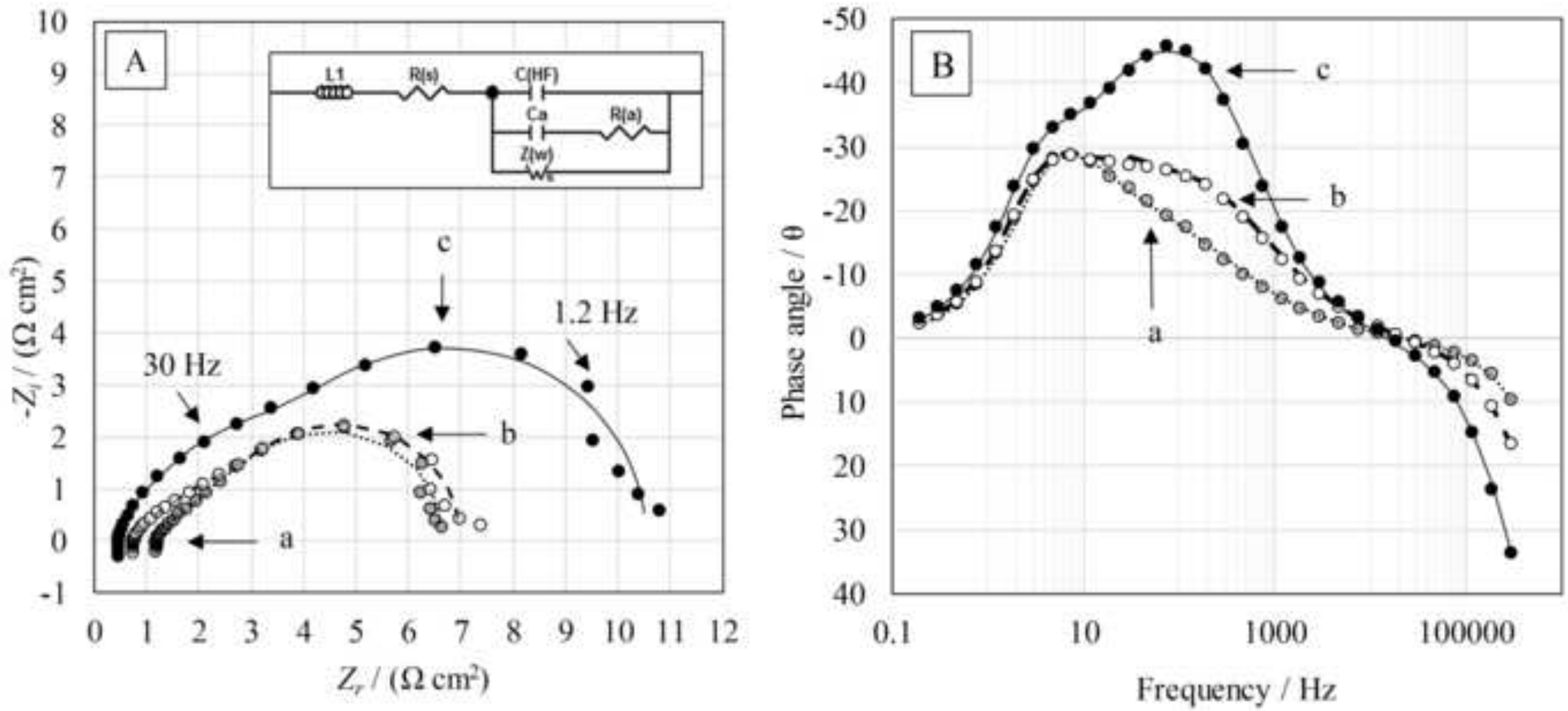